\title{
Digital Orange: Understanding the Posthuman by Culturally 'Telling' Time
}

\author{
Tom Chet
}

\begin{abstract}
In a world of instant gratification, cyberspace and internet wormholes, our altered sense of time is part and parcel of a new mentality, that of posthumanity. Our formulation of the concept of time seems a priori in relation to other ideas through which we comprehend our world yet most current theoretical frameworks of posthuman research disregard time entirely, focusing instead on denying dualism and generating models towards building a better future. However, through a cultural reading of our current temporalities, defining our posthuman reality, I will outline our new world view - built upon, multiplicity and connectivity. Thus suggesting a new avenue of research focused on what we have become, instead of what we aspire humanity be.
\end{abstract}

Index Terms-Digital-age, narrative, popular-culture, posthuman, time.

\section{INTRODUCTION}

The best possible time to contest for what the posthuman means is now [1].

While in the past researchers questioned what it means to be human, today questions arise regarding the meaning of being posthuman. Within this digital-age we long to fathom how to interpret ourselves yet the notion of 'humanity' has become ever more elusive. In an attempt to generate a clear idea of what it means to be part of this digital era we seem to have lost our way - focusing on ethics, human and animal rights, our intimacy with technology and the ever-persistent question of embodiment, in order to define our posthuman existence. While all these are relevant, they result from a shifting world view caused by our varying notion of time, which, I believe, is fundamental to our posthuman existence.

As we utilize time to order and make sense of our lives, the shifts in our ideas and uses of time affect our mentality as well as our cultural and political environments. We can look to moments in our cultural history, such as the ten hour movement, or the introduction of daylight savings time during WWI, or even the invention of the watch, to see how impactful such changes have been on humanity as a whole. The concept of time seems a priori in relation to other ideas through which we make sense of the world, hence time's fundamentality in the creation of our posthuman mentality.

Time remains a way to measure productivity, a useful tool for organizing people as well as schedules yet it is also much, much more: in a society that emphasizes connectivity - from creating ties to the right people, forming online communities, to continuously maintaining an online presence - today, time

Manuscript received July 21, 2015; revised October 1, 2015.

Tom Chet is with the English Literature Department, University of Tel-Aviv, Israel (e-mail: timtam.ch@gmail.com). truly is everything. In cyberspace all that matters is what is happening in the 'now' and we can even track our own online activity on social media by this standard, with a conveniently located clock telling us how many minutes passed since we made our online presence known. Time is being stretched, with every moment forced to encompass all of reality, as we move away from a linear understanding of time.

Through a study of popular cultural I wish to illuminate how this shift in our notion of time generates a new way of being - creating our posthuman reality. In this paper I wish to better identify what it means to be a subject in the digital-age. I will begin by portraying the ideas raised in posthumanist research thus far and then move on to address the concept of time in general. Though I will not exhaustively review the influences on our comprehension of time throughout history, I will, briefly, present those especially influencing our current understanding of the concept of time, before moving on to portray how time may be viewed as molding the posthuman. In this manner, I suggest a new avenue for posthuman theory to expand into; instead of postulating how we should change or how we should be, I hope to emphasize the need to first fully comprehend what we have already become.

\section{POSTHUMANISM: Your Humanity IS SLIPPING}

In this temporalizing mode, posthumanism requires the human, it relentlessly calls it into being [2].

The boundaries of humanity are ever changing, enforcing the fluidity of the term 'human'. Entering the realm of the posthuman, it seems this quest becomes ever more central. At the onset of the digital-age, Western culture took with it the values from the enlightenment and modernist eras, defining the physical and legal human yet it is when these values come across the new posthuman reality that contradictions arise. Some things become obsolete as others are called into being: on the one hand, it seems no longer relevant to discuss privacy in the age of the internet yet on the other hand, the rise of cyber bullying is still a grey legal, and moral, area. Today, as we study the new technologies that makeup our lives, we must generate a new understanding of our values; or perhaps form completely new values in their stead. Indeed, many researchers are focusing on the cultural and social ramifications of various technologies and medias in an attempt to comprehend the current meaning of concepts such as privacy, voyeurism and so on [3], [4].

When considering the effects of new technologies, popular culture is instrumental, influencing our current formulation of the term 'human'. As we see superheroes, monster hybrids, zombies and vampires come to life on our screens, we are 
forced to address such questions regarding the changing values and identity formation in a posthuman age. When a super-natural being is set as the protagonist, the narrative is fundamentally addressing society's insecurities regarding the nature of human-kind: social and cultural values are enforced, as well as questioned, when self-discipline and altruism are pitted against instinct and self-preservation. In some cases this is made abundantly clear as, for example, in the CW show Beauty and the Beast [5], in which the genetically altered human, Vincent Keller, is turned into a beast operating on instinct; the number of times characters refer to his contentious and fragile humanity is innumerable [5]. This struggle for balance is not unique to narratives born of the digital-age yet these conflicts, central to each superhero, vampire and zombie narrative, seem to embody the current battle between past values and those finding root in society today.

While I will not go into detail in this paper about the particular struggles over various ideas and values, I do believe that studying cultural narratives best informs us of victories in this battle. However, the current theoretical framework of most posthuman theorists steers away from such readings and focuses instead on denying dualism and generating models for humanity, as they wish it to be [1], [6]-[9]. In this manner, ontological change is often portrayed as political. Posthumanism is thus reduced to a struggle over an image of the future and while we do need to find new ways to lead a 'human' life, this cannot be achieved before we understand who we have already become.

As posthumanists work against false beliefs set by humanist ideals, the need to address embodiment is emphasized in order to dismantle entrenched notions of a Cartesian separation between mind and body [1], [8], [9]. Yet focusing on embodiment keeps calling this separation into existence and thus, even in posthumanist research, bodies remain a site through which we judge difference; even if we accept political movements in the name of posthumanism, calling for continuously expanding our definitions of the 'human', we end up just defining another 'other' in the end. Hence, while distancing ourselves from what defined mankind in the past is necessary, we must question whether dismantling dualisms has any bearing on our new understanding of ourselves.

While some researchers seem to fall into this humanist trap, there are those who attempt to generate an understanding of posthuman existence, not based on merely undermining past ideals but by contemplating the fabric of our current reality. For example, E. Gomel [10], in Narrative Space and Time: Representing Impossible Topologies in Literature, discusses the impact of our changing understanding and experience of space on narratives and, in this fashion, establishes a way to read the meaning of being posthuman today. Though I find this research in line with my own, I believe the emphasis should be on time as a central element, rather than space. Still, there is a need to attest to the undeniable connection between these two concepts; they are not linked only thanks to Einstein's assertion of space-time.

In attempting to fully grasp the conceptual meaning of 'space' many philosophers assumed a linear progression of time without giving it a second thought, as an understanding of time is paramount in order to study movement and change. For this reason I chose to focus on time, as it seems to me primary in relation to other ideas through which we comprehend our world but both time and space may be understood as frameworks which allow us to make sense of our surroundings and hence, our selves.

\section{SynChronize Your WATChES - IT'S TimE}

Time can go forward again into life, but it can't be reversed back to where it was before [1].

The existence of time has been questioned throughout history, from Parmenides, to McTaggart, thinkers have made a claim for the unreality of time [11], [12]. Stepping away from a Newtonian understanding of time and space, these theoreticians postulate time as merely a framework aiding humanity to comprehend its own existence, rather than it being a part of 'true' reality. In this sense, time is understood to be a necessity of human thinking, as our senses generate a temporalized configuration of the world. Yet, while some advocated the non-existence of time altogether, there were those who insisted time exists but perhaps not as we would expect.

According to Mellor [12], McTaggart's evidence regarding the unreality of time only provides proof of the unreality of time-flow, from future, to present, to past, suggesting a variance on our concept of linear time. This analysis leads to a presentist understanding of time, where only what is in the 'now' is real [13]. Thus, what we have seen throughout history is a reduction of time to information - as in posthuman theories, to human error, to a model through which to order reality, to an imaginary entity, all of which was later consumed under Einstein's notion of space-time: " $[\mathrm{t}]$ he philosophical consequences of this reduction of time to space is determinism" [10].

While I do not wish to flatten time into a mere physical existence, spatial and technological correlations to the concept of time are not irrelevant, in part, due to the pervasive idea of space and time operating in concert. For instance, virtual reality is created spatially as well temporally, as we use devices to connect to what we envision as a net, or a network, and every action is time stamped and time coordinated. While some view a study of time as necessitating an elimination of all things spatial - that in order "to think of the digital in terms of time, we first need to overcome the tendency to spatialize the process of interaction with digital systems," I disagree [14]. I will indeed be focusing on time in this paper but I do not think that we should forcibly ignore elements connected to our experience of time just because they are physical in some way, else we would be segregating time to the Cartesian qualification of the mind.

Considering the impacts of technological advancements is just as important as the impact of philosophical theories of time, as the current popularity of quantum theories likely influence the way we now perceive time (particularly regarding notions of multiplicity). Just as the advancement of online shopping alters not only our increasing penchant for immediacy but also how we categorize our time - we can buy 
shoes while on the toilet without having this fracture our sense of world-order. However, my aim remains, at this stage, to focus on a cultural understanding of time:

We tend to think of the assault on our temporal sensibilities as a recent phenomenon, something that happened since the advent of computers and cell phones $[\ldots]$. But as technology and culture theorists have reminded us at each step of the way, all this started much, much earlier [... as] what it meant to be a human being changed along with however it was - or through whatever it was - we related to time [15].

Hence, a cultural reading of time helps form a coherent understanding of what it means to be posthuman today.

\section{OUR REALITY: IT'S NOW OR NEVER}

"Everyone else $[\ldots]$ is at one with the moment, $[\ldots]$ and I'm there, running, thinking 'well, this will probably make a good memory' - which is living in the future discussing the past with someone, who if they asked you 'oh what did it feel like?' - 'I don't know! I was thinking what to say to you!'، [16]

When we find ourselves chasing memes on the internet, or spiraling in an endless stream of videos - one click leading to the next, we are experiencing how our altered sense of time is part and parcel of a new mentality, which I view as the essence of our posthumanist perspective. The digital-age seems to dictate a time-flow of its own, due to the different elements that mediate our reality, alongside time itself: " $[\mathrm{t}]$ ime in the digital era is no longer linear but disembodied and associative" [15].

This disembodiment is related to the globalization of time - while a global system of time, utilized through digital mediums, allows for a higher level of globalization than ever before, it is not only space that is affected: within this digital-age any point in space is, in some ways, accessible anywhere at any point in time yet time itself is also being stretched to incorporate all the actions taking place around the world in a single moment. Our lives are filled with feeds importing all the latest and most relevant information, our Facebook walls track our lives and those of friends in relation to the present moment to show us the most relevant thing happening right now - our sense of the present is stretched infinitely as we add on any data that suddenly becomes part of the 'now', hence becomes relevant. It is not merely that we are now online $24 / 7$, or that we are connected to people living in completely opposite time-zones, it is that all this informs our reality within a carefully timed yet timeless world.

This type of presentism incapacitates a linear comprehension of time. That is not to say that the words past, present and future have lost all meaning, but that their meaning has been significantly altered. One example is in this idea of the globalization of time - it is not conceivable to order all the data at our fingertips chronologically, moment by moment, while taking into account all the different time zones and the like; and we would find this irrelevant if it were possible. When we look to see what is trending right now, we only care about our perception of the present moment, hence our belief that we are seeing all the information needed for us to comprehend what is happening around us in the world.
We do not exactly achieve a linear temporality, rather we have created a multi-temporal reality based on the importance of relations, a type of inter-textuality and inter-activity. This may be viewed as directly stemming from digital technologies: "the multi-temporality of the digital presents an alteration to the way we experience the occasions and events of our everyday lives, beyond a chronological sequence of events" [14]. While we create sequences, they are no longer strictly tied to chronology; in general, something becomes important if it is: a) happening now, or b) being talked about now. Multi-temporality infuses most aspects of our lives, even our minds.

In this digital era the computer is god and man is in the midst of a race, 'cold-war' style, against the machine; "[i]f the clockwork universe equated the human body with the mechanics of the clock, the digital universe now equates human consciousness with the processing of the computer" [15]. We can see today how we continuously liken the human mind to a computer, from advertising to canonical popular culture imagery, reestablishing this comparison regardless of its inaccuracies. For example, in the recent BBC adaptation of Sir Arthur Conan Doyle's Sherlock Holmes, as the character of Sherlock works out the problems in his head, the screen displays the process as if it were a computer, thus equating his mind to a machine [17]. We see how the mind is perceived as a computer yet this depiction is also attempting to prove the mind's superiority - after all, Sherlock is a genius and therefore he has not been replaced by a deducing robot (for now).

Mankind is at once striving to create artificial intelligence (AI), while seeing itself as a rival to any such possible creation - the Turing test in itself imbues the entire race to create AI with rivalry. In this sense, it appears that:

Instead of demanding that our technologies conform to ourselves and our own innate rhythms, we strive to become more compatible with our technologies and the new cultural norms their timelessness implies [15].

This timelessness seems to be erroneously reliant on a continuous synching with a coherent temporality; as anyone can attest if an incorrect time setting caused their computer to malfunction. We have seen how the streams of data that reach us are all time-stamped and yet this does not have to dismiss the sense of timelessness we continuously experience through digital aids.

If we accept that multiplicity is not only an attribute of time but of our current mindset in general, then we can understand our contemporary modes of thinking as based on acceptance of dualisms: we are constantly assured we are all unique, which means none of us is special, we care only for the present yet we live through cataloguing it into the past, our world is ordered through a conceptualization of timelessness yet with a strict timed-flow of information. While postmodernism sought to eliminate dualisms, we now find they are not so much eliminated as, perhaps, incorporated in a manner that creates a multi-layered reality; especially considering that connectivity is the essence of today's cultural framework [4].

Even our investment in connectivity is a result of oppositional components which must be accepted as simultaneous: "we are slowly connecting everyone to 
everyone else and everything else. Of course, once everyone is connected to everyone and everything else, nothing matters anymore -" the same as with the issue of uniqueness [15]. Connectivity, as much as multiplicity, is essential to posthuman mentality yet it is also important to note that, "in a technological sense, connectivity is about the quality of connection, rather than about the nature or quality of content" [4]. As tagging and hashtagging enforce response-driven behavior online, we can see how content is created through context and relations, all unfolding in the present moment. This manages to turn a young adult postmodern fantasy into reality, allowing one to be part of a community while retaining one's own voice: by adding an opinion to a thread one can feel linked to an online community without endangering one's sense of 'self'.

This importance of connectivity and hence of generating content through a superimposing framework, calls into question our understanding of the current culture's obsession with the 'now':

As individuals, our efforts to keep up with the latest Tweet or update do not connect us to the present moment but ensure that we are remaining focused on what just happened somewhere else [15].

Whether we utilize 'the moment' to connect to a different space in time, to a different time in history or to a different mode entirely, such as when one spends a train trip reviewing and editing images that makeup a virtual identity, we are not 'living the moment' in the traditional, humanist, sense. Rather, as time is no longer perceived through a simple linear progression, our narratives are now formed through ideals of connectivity, such as inter-textuality; attempting to explain our own existence by managing to string together thoughts, ideas and events from different times and places to create a coherent image of the present. In this respect, the present moment is not about 'smelling the roses' but about cataloguing and referencing each rose to create a bouquet of meanings, to later be scrolled through in a moment of boredom.

\section{NARRATIVE LOST, NARRATIVE FoUnd}

There are so many plots, in fact, that an ending tying everything up seems inconceivable, even beside the point. [15]

To fully review the concept of time, as perceived through popular culture, requires that we also address how our new conception of time affects our narrative framework in turn. I am focusing on narratives as it is through stories that we explain our lives to ourselves: "[e]xperiencing the world as a series of stories helps create a sense of context" [15]. Traditionally we understand narratives to include a beginning, middle and end, which are set up linearly.

This may have happened because the linear structure is essentially true to life, or we may simply have gotten so accustomed to it that it now informs the way we look at events and problems that emerge [15].

This form of narrative is so deeply entrenched that according to D. Rushkoff's analysis of temporality in the digital-age, we are now experiencing narrative collapse, due to the disintegration of linear time through which to tell stories: "[n]arrativity is just the first of many things obsolesced by presentism, [as we experience] trauma at losing linearity" [15].

According to Rushkoff, in place of linear narrative we are left with an attempt to utilize our need for connectivity to make sense of our surroundings through patterns [15]. He claims this calls into being a balancing act: "We find nearly every corner of popular culture balancing the welcome release from traditional storylines against the pressure to produce similarly heightened states without them" [15, p.38]. Yet, can we truly escape, or leave behind, the traditional narrative categories and formats if "even brain scientists came to agree that narrativity is an essential component of cognitive organization"? [15]. While I concur that there are alterations to the narratives generated in previous eras, I find no reason to dismiss the existence of narratives altogether. For example, while Rushkoff asserts that reality TV is an example of the decay of narrative in the digital-age, I find that it is rather a striking example of how fundamental elements of narrativity remain intact [15].

Recently, Lifetime aired a fictional show, named UnREAL [18], depicting the life behind the scenes of a reality TV show. As they expose the reality behind this 'reality' programming, we are faced with the truths we already knew - these shows are in many ways scripted. Though not written by writers, the crew hand pick characters to fit a prescribed narrative and then manipulate contestants and footage to continuously create 'good TV' (in this context meaning creating a coherent story for the fans). In this instance, as the show centers around the fantasy of finding true love, the contestants are hand-picked to match the predictable labels: marriage material, virginal, aggressive minority, classy minority, crazy, temptress and the one everyone hates. This configuration clearly illustrates the manner in which narrative frameworks maintain a hold on us even with the collapse of linear time. Perhaps this is more habit than necessity but, either way, we continue to understand ourselves and our world through narrative models.

We may also look at the endurance of traditional fairytale narrative models as examples of this, as they lend themselves to continuous alterations through the ages yet remain unerringly recognizable. The Cinderella-story, for one, has been retold countless times in various manners. A recent adaptation by Marissa Meyer, Cinder [19], retells this classic tale of rags to riches from the perspective of a cyborg, named Cinder. As the narrative unfolds, this cyborg heroine introduces the readers to a post-apocalyptic future world and while the narrative contains more potent social criticism, heightened by the text's setting, the recognizable narrative framework of a Cinderella-story is evident. Though this is done by design, the mere fact we are still retelling such stories proves the continued interest in generating narratives. My main interest in this adaptation, however, lies in the elements that were altered - here we have a technologically enhanced character who we accept as a reliable narrator in spite of her being cyborg. Perhaps this is due to our comfort with the imagery of the human mind as a computer, or perhaps, as we are now all imbued with a technologically altered view of reality, we are simply cyborgs at heart (or in mind). 


\section{CONCLUSION}

This paper is only an overview and does not allow for nuances that would form a more accurate and detailed portrayal yet, in order to comprehend the modes of thought embedded in posthuman subjects, it is imperative to further address cultural narratives and phenomena as they shape, as well as reflect, our current mentality. By focusing on 'telling time' while studying popular culture we can achieve a better understanding of the current human condition, which is necessary for any attempt at generating future change.

By focusing on narratives that are being produced today we can see how questions, such as of good or evil, are deemed irrelevant; not only with regards to technology, they are even being made irrelevant for villains, as narratives now strive to encompass multiplicity. We are constantly re-introduced to 'evil' characters as they tell their side of the story; like in Wicked: The Life and times of the Wicked Witch of the West [20], or even in the recent Disney film Maleficent [21], which humanize these previously purely evil characters. Thus, multiplicity is not only a part of our concept of time - it has become a central mode of thinking. Our digital and temporal reality colors our view of the world and just as everyone's opinion has a place in cyberspace, every villain can be made into a hero - but more importantly, we wish to see this reversal take place. It has always been true that there are two sides to every story yet today we have an interest in accepting both as existing simultaneously.

As we move away from our instinctive understanding of linear time, the accompanying shifts in values, norms and modes of thought, contribute to the anxiety surrounding 'being human'; propagating the need for familiar plot structures. Yet, while fundamental narrative components and themes are retained, they are imbued with a posthuman perspective through the introduction of multiplicity, connectivity and multi-temporality. Just as 'evil' is no longer dichotomous with 'good', oppositional categories are being inhabited simultaneously through advancements in technology and changing modes of thought but the resulting uncertainty is precisely what fuels the underlying unease of this posthuman era - how can one be more than just one side of a story?

While familiarity is comforting, having multiple identities online, interconnecting one's documented experiences with others, creating various virtual realities in which one can exist differently, is protection. For postmodernism the fractured self was key yet in the digital-age each fragment becomes an identity, an avatar, with endless possibilities, ensuring one can always fit in. Instead of remaining contained, our various selves attempt to mimic multi-temporality - leaving humanity behind.

\section{ACKNOWLEDGMENT}

I would like to thank Prof. E. Gomel for her mentorship and guidance. In addition, I would like to thank all those who listened, read and re-read, cajoled and, most importantly, cared - you know who you are.

\section{REFERENCES}

[1] K. N. Hayles, How We Became Posthuman: Virtual Bodies in Cybernetics, Literature, and Informatics, University of Chicago Press, 2008.

[2] B. Braun, "Querying posthumanisms," Geoforum, vol. 35, no. 3, pp. 269-273, May 2004.

[3] H. Koskela, "Webcams, TV shows and mobile phones: Empowering exhibitionism," Surveillance and Society, vol. 2, no. 2/3, pp. 199-215, 2004.

[4] J. V. Dijck, "Facebook and the engineering of connectivity: A multi-layered approach to social media platforms," Convergence: The International Journal of Research into New Media Technologies, vol. 19, no. 2, pp. 141-155, Sep. 2012.

[5] "The beast of wall street," Beauty and the Beast. CW. Creator Sherri Cooper- Landsman, Ron Koslow and Jennifer Levin. 7 June 2015, Television.

[6] R. Braidotti, The Posthuman, John Wiley \& Sons, 2013.

[7] B. Clarke, Posthuman Metamorphosis: Narrative and Systems, Fordham University Press, 2008.

[8] S. Vint, "Bodies of tomorrow: Technology, subjectivity," Science Fiction, 2007.

[9] C. Wolfe, What Is Posthumanism? vol. 8, U of Minnesota Press, 2010.

[10] E. Gomel, Narrative Space and Time: Representing Impossible Topologies in Literature, Routledge, 2014, pp. 1-38.

[11] A. H. Coxon, The Fragments of Parmenides: A Critical Text with Introduction and Translation, the Ancient Testimonia and a Commentary, Las Vegas: Parmenides Publishing, 2009, pp. 48-97.

[12] D. H. Mellor, Real Time II, London: Routledge, 1998. ch. 7-8, pp 70-96.

[13] N. Markosian, "A defense of presentism," Oxford Studies in Metaphysics, 2004, ch. 3, pp. 47-80.

[14] T. S. Barker, Time and the Digital: Connecting Technology, Aesthetics, and a Process Philosophy of Time, UPNE: Dartmouth College Press, 2012, pp. 1-28.

[15] D. Rushkoff, Present Shock: When Everything Happens Now, Penguin, 2013.

[16] P. S. Amstell and S. Amstell, Do Nothing, Youtube, 2013.

[17] C. M. Gatiss and S. Moffat, Sherlock, BBC, July 25, 2010.

[18] C. S. G. Shapiro and M. Noxon, UnREAL, Lifetime, June 2015.

[19] M. Meyer, Cinder, New York: Feiwel and Friends, 2012.

[20] Maguire, Gregory, Wicked: The Life and times of the Wicked Witch of the West: A Novel, New York: Regan, 1995.

[21] Maleficent, Production: Roth Films, Walt Disney Picture, Motion Picture, May 29, 2014.

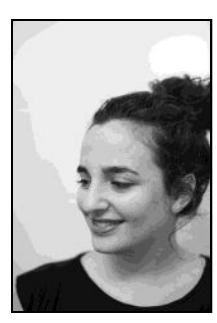

Tom Chet was born in Wilmington, Delaware, USA, in 1989. She completed her BA in English literature and anthropology-sociology from Beer-Sheva University, Israel, 2013. She attended the University of Edinburgh, Scotland, in 2011 for an English literature program and King's College, London, England, for a Children's Literature program, in 2012. She is currently completing her MA at Tel-Aviv University, Israel, in English literature - focusing on posthumanism, young adult literature and popular-culture, while addressing questions regarding humanity and cultural phenomena in the digital-age.

She served in the Intelligence Bureau, Israel Defense Forces (IDF), from 2008 to 2010. She worked as a general manager and marketing director at WERPO, a green energy corporation, from 2013 to 2015. She presented papers in the 2014 MPCA and NEPCA conferences, in Indianapolis and Rhode Island, respectively.

Ms. Chet is a member of the Popular Culture Association (PCA), from 2014, and an alumnus of King's College, London, England. 